\title{
A House Divided against Itself Cannot Stand: Evaluating Police Perception of UK Missing Person Definition
}

\section{Karen Greene, Lynsey Hayler, David Pritchard}

\section{Introduction}

'Missing persons' is a phenomenon that takes place on a daily basis, impacting people from every walk of life, regardless of cultural, educational, financial background or geographical borders. People go missing for a wide variety of reasons which can be explained by social causes as well as psychological reasons (Moscovici \& Halls, 1993; Morewitz \& Sturdy Colls, 2016; Shalev Greene \& Alys, 2016). However, they all share an absence, recognised by another person who may or may not report it to the police (Edkins, 2011).

The issue of missing persons in the UK is a routine part of police work, and is extremely resource intensive, costing the police overall more than theft or assault investigations (Shalev Greene \& Pakes, 2013). Most people who go missing are found safe and well and return within the first 24 hours. Yet, the majority of people who go missing are vulnerable due to their age, mental health or risk of abuse or neglect, and a vast number of them are recipients of social welfare provisions prior to going missing (Holmes, Woolnough, Gibb, Lee \& Craword, 2014; Stevenson, Parr, Woolnough \& Fyfe, 2013; Butler \& Parr, 2005).

Despite the phenomenon of missing persons being transnational, there is currently no universal definition of the term. The importance of standardising definitions is well recognised across law enforcement agencies. The United Nations Office on Drugs and Crime (UNODC) (2015), for example, notes that its International Classification of Crime for Statistical Purposes (ICCS) seeks to standardise definitions of crime across different countries for the purposes of comparative analysis as it seeks to develop the consistency and international comparability of crime statistics, in order to improve analysis at national and international levels (UNODC, 2015). 
Although going missing is not a criminal act, the agency almost always tasked with locating missing person is the police. Currently, the way in which statistics regarding missing persons is generated depends on the specific definitions used by each country in relation to this phenomenon. Therefore, the lack of an agreed upon definition of the term makes it difficult to know the full extent of the missing problem globally or assessing comparability between countries.

However, the discussion about a definition of a missing person goes beyond examining the limitations of current recording practices by police forces or biases and distortions in generating official statistics (Hope 2007, 2014). The standardisation of a missing person definition is intrinsically linked with identifying which agency has the 'duty of care', thus impacting on the response to a missing person report in terms of prevention of harm and safeguarding activities (Hayden \& Shalev Greene, 2018).

In order to address the lack of international standards and guidelines on protecting children from going missing, the International Centre for Missing and Exploited Children (ICMEC) initiated in 2011 a series of regional reports titled the 'Global missing children research initiative'. It examines laws, national strategies and country-specific mechanisms that exist for addressing missing children around the world (2011, 2015, 2016 a, b). In 2013, the European Commission (EC) published a study that analysed statistical data from EU Member States on missing children, together with clear information on the definition according to which they are collected, the circumstances in which data are collected, by whom and from whom (p. 7).

These studies focus on missing children. We contend that having a clear definition is relevant to all missing persons, regardless of their age. Furthermore, these studies map out definitions, statistics, policies and practices aiming to develop comparative data between countries. We 
argue that in addition to these efforts we must also evaluate what are the components that ought to be included or excluded from such a definition.

Nonetheless, these studies alert us to a number of important issues. First, countries such as Cyprus, Denmark, France, Greece and Spain do not provide any official definition of a missing person. Thus, it is up to law enforcement agencies to decide whether and under what circumstances a certain case should be considered a missing person (EC, 2013).

Second, the majority of countries do not have a binding legal definition of what constitutes a missing person. Definitions can be provided in law (e.g in Cambodia, Estonia, Hungary, Ireland, Guatemala, Russia, South Korea, United States of America, etc). However, the legislation varies in scope. For example, countries such as Canada have provincial legislation rather than federal as in the USA. Yet, most definitions are provided in police regulations or policy (e.g, in Belgium, Bulgaria, Costa Rica, Malaysia, Latvia, Philippines, Poland, Singapore, United Kingdom, etc) (EC, 2013; ICMEC, 2011, 2016a, 2016b).

Third, the level of detail included in the definitions varies substantially. Some definitions are based on the type of disappearance and/or the level of risk connected to the disappearance. For example, whether the person is thought to have runaway, been abducted, or is lost or injured. The most common elements of current definitions are the lack of information about the whereabouts of the individual and whether or not there is concern for their wellbeing as well as whether they left voluntarily or not (EC, 2013; ICMEC, 2011, 2016a, 2016b).

The authors of these studies stress that understanding how and when a person is considered 'missing' are fundamental for ensuring that police and other agencies undertake accurate recording. The EC report (2013) recommends that the definition of a missing person should provide a legally binding law and hold a common currency across different sectors; including the judiciary, border agencies, care institutions and child welfare organisations, and that front 
line police officers should have at hand manuals with clear operational definitions of when a child has to be reported as missing, and how the circumstances should be recorded and managed in order to ensure consistency and transparency.

In the UK, the police respond to over 300,000 missing person reports each year, relating to over 150,000 individuals, with children representing around two thirds of the total number of cases (National Crime Agency, 2016, 2017). While the EC (2013) study found that the highest number of cases of missing children per total number of children was in Hungary and the Republic of Ireland, the UK had the highest total number of missing children reports of all EU member states. Given the high frequency of occurrences, and that the definition is provided as policy and is not age specific, the present study uses the UK as a case study and examines, for the first time, police officers and civilian staff's views of the current missing person definition.

\section{Conceptual Framework}

Social policy is an aspect of public policy and it refers to actions and positions of the state. It is the product of a series of decisions taken by political actors, following the identification of a social problem or need. Barton \& Johns (2012) state that once something has been defined as a 'problem', there is a political pressure to act. The activities of the state seek to enhance the welfare of its citizens through diversion of resources to and the promotion of care of dependent groups (Hobbs \& Hamerton, 2014). However, there are likely to be conflicting opinions of the nature of the 'problem' and the perceived solutions. The decision of whether or not to apply a social welfare or a criminal justice solution and/or medicalise solution is a political one that reflects a combination of ideological preferences and pragmatic considerations (Hobbs \& Hamerton, 2014). 
At first glance, it can be contended that social policy and criminal justice policy are mutually incompatible (Newman and Yeates, 2008). Social policy is concerned with social welfare and the well-being of citizens. On the other hand, criminal justice policy focuses on the detection and reduction of crime and related societal harms. The key institutions of concern for social policy include health, education, housing, social security, and social services. In comparison, criminal justice policy is concerned with the police, courts, prison, and the other arms of the criminal justice system. Both social policy and criminal justice policy are also concerned with justice within society, albeit different models of justice. Social policy draws our attention to social justice, principles of equality and fairness, social inclusion, and well-being. Criminal justice policy by its very nature is concerned with the principles of due process, the maintenance and delivery of security, and crime control.

Non-crime incidents account for $84 \%$ of all command and control calls (College of Policing, 2015). In effect, this refers to public safety and welfare - mental health, child protection, missing persons and suicides. The work of Vitale (2017) recognises the plethora of social problems that the police are expected to respond to. In fact the End of Policing thesis contends that policing, albeit it in the sense of more police officers, more oppressive laws, and the continuation of the criminalisation of the marginalised, is the wrong approach.

We contend that the process of the socialisation of criminal justice policy is identifiable in policy relating to missing persons. Important aspects of policy and procedure relating to locating a missing person are primarily concerned with the welfare and well-being of the person in question.

The Curious Case of Missing Person Policy 
Despite this social 'problem' being acknowledged across the UK and identified by previous governments (All-Party Parliamentary Group on Runaway and Missing Children and Adults, 2017; Home Office, 2011), there is no agreed upon definition of a 'missing persons' that is shared across all public sectors. The only formal definition is written within the policy issued by the College of Policing (2016). Thus, in the UK, the 'Missing Persons' policy is placed within the criminal justice system, with the police being identified as the responding agency that is expected to investigate and locate a person reported missing.

The policy, including the definition of a missing person, changed three times since 2005 (see table 1).

Table 1: Insert here

Barton \& Johns (2012) claim that such policy change should be a result of policy learning. However, policy change is often a result of ideological or interests change and the exercise of power (Moyson, Scholten \& Weible, 2017). Howlet, Ramesh \& Perl (2009) explain that, in order to achieve policy learning, a policy needs to be evaluated to ensure that the goals of the policy are being met and, if necessary, the original policy can be re-formulated to take into account the findings of the evaluation.

This is because, once the policy is put in place it becomes part of an increasingly messy 'real world' system which contains ambiguities, uncontrollable events, interpretation gaps, that can overtake and undermine the policy (Bovens, Hart \& Kuipers, 2006; Freeman, 2006). To date, there has been no empirical evaluation of any of these policies (table 1).

The current 'missing person' policy has five sections (College of Policing, 2016). The first section defines the term. The second section sets a framework for risk assessment and response to be carried out by law enforcement agencies. The third section constitutes a 
statement regarding joint responsibility between police, parents and carers to take reasonable actions to try and establish the whereabouts of individuals who are missing. The fourth section of the policy sets the minimum actions that will be undertaken in all missing person cases. The fifth and final section identifies the national specialists support available to police forces. The aim of this article is to evaluate the first section of this policy, which is the definition of a missing person.

The charity, Missing People (n.d), rightly argue that the difficulty in providing a definition stems from the wide variety of potential reasons behind a person going missing, and the different ways an incident may be understood by different parties, such as police, social services, health services, etc. It is also reasonable to suppose that the diverse interpretation and/or a lack of common understanding of the 'missing persons' definition have led to inconsistencies in police practices in investigating missing person cases (ICMEC, 2015). This may leave some people at risk of serious harm and varied experiences in terms of offer of support once they return (Her Majesty's Inspector of Constabulary and Fire \& Rescue Service, 2016; Stevenson et al., 2013).

The challenge is that a definition that is too restrictive excludes people who are vulnerable and should be included within the framework to be searched for by law enforcement agencies. A definition which is too inclusive dilutes the term, comprising of people who do not require the assistance of the police and impacts the workload of operational policing. Such increase in work demand leads to the draining of valuable and depleted resources, following difficult economic conditions across the public sector and police budget cuts (O’Hara, 2015).

Developing a policy that can be successfully implemented across vast and complex organisations such as the police, social services or local authorities is not easy. Dorey (2005) 
lists eight prerequisites for the perfect implementation of policy. These are equally useful in understanding what can cause policy to falter or even fail. First, external agencies or events do not pose major constraints. Second, those charged with implementing a policy are independent from other agencies. Third, there is minimal number of decision points in how to interpret the policy, since no policy can cover every possible scenario. Four, resources such as money, staff, time and knowledge are adequate. Five, the policy is based on a valid theory of cause and effect. Six, the aims and objectives of the policy are clear, coherent and consistent. Seven, the objectives are fully understood and or accepted by those expected to implement it. Eight, those at whom a policy is targeted respond in the expected manner.

As Dorey (2005) states, a perfect implementation is unattainable in the real world, and as a result policies almost always suffer from 'the implementation gap', which is a gap between the way a policy is formulated and the manner in which it is delivered. The reason lies with those who are charged with its implementation, because they understand through their experiences why the problems often arise or become apparent (Dorey, 2005).

The Street Level Bureaucrats

Lipsky (1980) coined the term 'street level bureaucrats' to describe the workers, or in our study, police officers and staff, who see themselves as cogs in a system oppressed by the bureaucracy within which they work (Lipsky, 2010). These workers often feel alienated, without much control over resources, pace of work and unpredictability of demands (Hill \& Varone, 2014).

Yet, the 'street level bureaucrats' are not passive functionaries or line managers, simply applying regulation or enforcing legislation. On the contrary, street level bureaucrats often have large degree of autonomy and discretion which enables them to interpret the policy and shape policy outcome to fit their own goals, ideologies as well as their organisation's goals 
and ideologies. As a result, policy on the ground can often look very different from the manner in which it was envisaged during the planning phase (Barton \& Johns, 2012, pg. 81). This was supported by Smith \& Shalev Greene (2015) who found that police officers in three English police forces expressed dissatisfaction with the ACPO (2013) policy relating to missing persons and found it difficult to understand and implement.

While we encourage public discussion about whether missing person policy should be placed within the criminal justice system or not, and whether the definition should be provided as policy or legislation, this study will examine the content of a missing person definition. Such analysis goes beyond the issue of placement of the definition and it is relevant to other countries. In order to understand the challenges in utilising this policy and advance policy learning, the study focuses on the 'street level bureaucrats', i.e. police officers and civilian staff and how they perceive the definition of missing persons. The specific questions being examined are threefold: (1) How suitable is the current definition? (2) What are the limitations of the current definition? (3) What components should be included in a future definition of a missing person?

\section{Method}

\section{Sample Data}

The current study uses data collected from an 'Online Surveys' (formerly known as Bristol Online Surveys) of 406 police officers and civilian staff based in England, Wales and Northern Ireland. The survey was administered between $16^{\text {th }}$ November 2017 and $14^{\text {th }}$ December 2017. The University of XXX's Ethical Board reviewed and approved the survey protocol and data collection instrument prior to data collection. 
The data collection process was carried out using a snow ball sampling method. An invitation letter with a link to the online survey was sent to gatekeepers from law enforcement agencies. The manager of the Missing Persons Unit (National Crime Agency) posted an invitation to participate in the study on the Police Online Knowledge Area (POLKA), which is a secure online collaboration tool for the policing community to network (College of Policing, 2017). The National Police Chief's Council (NPCC) Policing lead for Missing Persons made contact with all Chief Constables requesting them to communicate internally with officers and staff and alert them to the study. Study inclusion criteria were working as a police officer or police staff within the geographical borders of England, Wales and Northern Ireland. Participation in the study was on an opt-in basis and all responses were confidential and anonymous. The survey took approximately 10 minutes to complete.

Measures

Policy analysis is a process of inquiry aiming at the creation, critical assessment and communication of policy relevant information. Policy analysis is partly descriptive in understanding 'what is'. It also relies on normative reasoning to examine that 'what ought to be'. Policy analysis is designed to provide information about a number of different types of questions, such as policy problems (e.g. identifying what is the problem with existing policies for which a solution is sought) and preferred policies (e.g. what policies should be chosen to solve the problem?) (Dunn, 2015).

Thus, police officers and civilian staff's perception of the College of Policing (2016) policy were measured using fifteen questions. Three questions related to the missing person definition. Participants were asked to indicate (1) whether they thought the current definition of a missing person is 'a good one'. Answers were on a 3 point scale of (a) yes (b) no (c) I don't know. The other two questions were open ended and respondents were asked 'what 
elements of the definition do you think captures the term 'missing person' well; and 'which, if any, element/s do you think needs to be added or changed.

\section{Sample Characteristics}

Coding included, participants' sex (male, female, transgender male, transgender female, other, prefer not to say), position within the police (police officer, police staff), police officer rank (police constable, sergeant, inspector, chief inspector, superintendent/chief superintendent, assistant chief constable/ deputy chief constable/ chief constable), geographic location (England, Wales, Northern Ireland), years in service $(1=$ under 1 year, $2=1$ to 5 years, $3=6-10$ years, $4=11$ to 15 years, $4=16$ years or more), number of missing person cases in an average week ( $1=$ none, $2=1$ to $5,3=6$ to $10,4=11$ to $15,5=16-20,6=21$ or more).

\section{Statistical Analyses}

Descriptive analysis was used for the sample characteristics and participants' perception of the definition as 'a good one'. Second, chi-square tests were used to compare the sample characteristics and their geographical location as well as respondents overall perception of the definition. Third, thematic analysis was used for answers of the open ended questions, as it offers an accessible and theoretically flexible approach to analysing qualitative data. Themes were identified using an inductive approach, whereby themes were identified from the data itself. A theme was identified as a patterned response which captured an important element. Prevalence of responses within each theme was then counted (Braun \& Clarke, 2006). Coding was carried out by the second author and verified by the first author. Analysis was conducted with SPSS version 24.

\section{Results}




\section{Sample Characteristics}

Sample characteristics are provided in Table 2 according to their geographic location. Overall, the majority of participants in this sample were male $(71.7 \%)$, serving as a police officer (93.9\%), ranked as Police Constable (50.7\%) or Sergeant (27.6\%), were over 16 years in police service (40.2\%) followed by 11 to 15 years (29.1\%). Most participants reported they were involved with 1 to 5 missing person cases per week (39\%), followed by 6 to 10 cases per week (19.9\%). The majority of participants were from Northern Ireland $(57.3 \%)$ and England (38.4\%), which does not represent the proportionate number of police officers working in these regions.

Table 2: Insert here

The results in Table 2 also indicate that participants from Northern Ireland were more likely to be male (99\%), working as a Police Constable (57\%) and were more likely to work on 1-5 or 6-10 missing person cases per week that their English and Welsh colleagues. It is also worth noting that a large proportion of English $(39 \%)$ and Welsh $(65 \%)$ police officers (versus $19 \%$ of officers from northern Ireland) are involved with 11 or over missing person cases each week, suggesting they work in specialist missing person units.

Participants' perception of the definition significantly correlated with their geographical location (see table 3). Participants from Northern Ireland held more negative views (71\%) (160 out of 224) about the current definition than their colleagues from England (60\%) (91 out of 151), whereas the majority of participants from Wales (65\%) (11 out of 17) considered the definition positively $(\mathrm{p}<.003)$. There were no other significant correlations between demographic background characteristics and perception of the suitability of the definition.

Table 3: Insert here 
The Suitability of the Current Missing Person Definition

Components that Capture the Term Well

A third of participants thought the current definition captured the term well $(n=122,34.8 \%)$.

Participants identified two components that they thought captured the term well. $31 \%$ (119 out of 301) of participants indicated they approved of the "whereabouts cannot be established'. Participants rarely elaborate on the reasons for this answer. The few that offered an explanation stated the term captures the absence of a person, which is what the term conceptually means. For example,

"Simply because this is what a missing person is."

"Makes perfect sense for someone who is missing."

Although a minority, 20\% (60 out of 301) of participants also approved of the 'well-being or otherwise confirmed' component, explaining it offers closure to the case, as well as acknowledges concerns for the person's welfare. For example,

"It indicated a degree of focus on the actual subject and their potential to be at risk."

Components that Need to be Added or Changed

However, the majority of participants $(n=262,65.2 \%)$ stated they did not think the current definition was good. Furthermore, 69\% (92 out of 301) of participants who responded to the open ended question stated they thought there was no element of the definition that captured the term 'missing person' well. Participants explained that, to them, the current definition was either too inclusive or too vague, and comprised of cases they did not consider to be a missing person. For example, 
'Because of its broad terminology, it's just easy to fit persons within that criteria'.

'Nearly everyone can technically be classed as missing when they are just late for an appointment, actively avoiding family they have fallen out with or wanted for a crime'.

Notably, some participants linked this limitation of the definition, as they perceived it, with the framework, police response to missing person cases, multi-agency work and impact on their workload. For example,

'The definition is very broad, and local protocols, partnership agencies need to be aware of their responsibilities prior to reporting a missing person, as otherwise police services could see a significant increase in reports.'

One of the areas that may be important to identify in a future definition of a missing person, is the distinction between a missing person and a person who absconds. According to Stewart \& Bowers (2010) absconding means a psychiatric patient being absent from the ward without official permission. This often includes patients who fail to return from leave. 5\% (17 out of 352) of participants argued that people who abscond from psychiatric hospitals or offenders who abscond from prison should not be considered as missing persons, and that the distinction between the two terms is not clear. For example,

"A distinction should be made between missing persons \& absconders from care homes. Absconders are not missing".

Interestingly, participants also referred to the phrase 'whereabouts cannot be established' as a source of confusion, due to being too general and open to interpretation. We may not know the whereabouts of our loved ones at any given moment but we would not be concerned for them or consider them missing. For example, 
'I don't think that 'whereabouts cannot be established' is a sufficient reason on its own to declare somebody to be missing. There should be some kind of aggravating factor included in the definition'.

In order to focus the definition further, 33\% (116 out of 352) of participants who answered the second open ended question, stated they thought the terms risk, vulnerability or concern for their welfare needed to be included. This is because when risk to a person's wellbeing can be identified participants considered it the police's roletobe involved in safeguarding activities. However, participants were also mindful that adults have the freedom to choose their whereabouts to remain unknown. For example, if they wished to lose contact with family members, spend some time on their own or if they were trying to escape abusive relationships. This 'freedom of choice', was to some participants, connected to a lack of risk, rending them as not missing. For example,

"There needs to be a degree of risk in the definition. If a person's whereabouts cannot be established but there is no risk why class them as a missing person. A person has a right to live their life without be sort by the Police using what can be considered intrusive measures. If there is "no apparent risk" why are we looking for them in the first place? The police are not a private investigating firm".

The element of concern for a person's wellbeing was also highlighted by 13\% (45 out of 352) participants who stated they thought the phrase 'out of character' should be made part of the definition. Participants explained that to them it was important to understand the context around a person's disappearance as this may assist them in establishing possible vulnerabilities of the person in question. Interestingly, one participant highlighted that this component contradicts people who go missing repeatedly as their disappearance would not be classed as 'out of character'. 
It is important to note that the ACPO (2013) definition of a missing person included both of these components and 7 participants explicitly referred to this earlier definition statingthey preferred it, or wished that definition never changed.

Another factor $10 \%$ of participants indicated was a wish that the definition would include an element of time (35 out of 352). For some, time meant a minimum time before a person can make a missing person report. For example,

"A timeframe should be allowed before a person is designated missing."

"An adult deemed capable of self-determination must be unaccounted for at least 24 hours before they are categorized as missing. Persons who walk out of a hospital without informing staff of their wish not to be treated will not be deemed missing persons unless there are mitigating medical factors".

For others, time was referred to in relation to evidence that the person reporting made initial effort to locate the person, prior to calling the police. For example,

"There need to be clear boundaries established regarding when a person's whereabouts have not been established and measures taken by the reporting person to locate them".

"Reasonable efforts need to have been made to locate the person".

The final component 29 participants discussed was the 'missing until located, and their wellbeing or otherwise confirmed'.

Participants raised two separate concerns. First, is the element of 'located' and what form of confirmation is expected of them. There is confusion as to whether a conversation on the phone, or a receipt of an email be sufficient, or does the word 'located' means that they must be seen physically by an officer. For example, 
'Define 'located', does this need to be a physical check or would a Skypelface time call suffice?'

The second concern was that the phrase 'well-being or otherwise' was confusing. A few participants suggested that the definition should directly state the person's physical and or mental well-being was confirmed, given the high proportion of people who go missing and suffer from disabilities or mental health illnesses.

\section{Discussion}

The results suggest that the majority of police officers and civilian staff do not consider the current definition as suitable. This is important because the negative sentiment is related to some extent to the participants' geographical location, with participants from Wales holding more positive views about the current definition than their colleagues from England and Northern Ireland. In this sample, police officers from Northern Ireland were more likely to have been serving for at least a decade, in roles that include constant response to missing person reports, alongside other policing duties. It is, therefore, possible that the negative sentiment is indicative of mental fatigue or disengagement with corporate procedures as was previously identified in three other UK forces in relation to missing person investigations (Smith \& Shalev Greene, 2015).

The general negative sentiment expressed by participants can be due to a number of reasons which may overlap. First, some police officers and civilian staff consider the inclusion of certain types of cases as not befitting what, in their view, should be the responsibility of the police. Thus, they express their disagreement with the socialisation of the criminal justice policy and a growing focus on welfare and wellbeing rather than crime reduction and control. Second, police culture tends to be resistant to change in general (Cohen, 2017). Harvey \& Broyles (2010) discuss 20 reasons why people resist change in their organisations. Of those, 
lack of ownership, lack of benefits, increased burdens, insecurity and ambiguity seem to be directly relevant to this discussion. Third, the current definition was deemed as not well defined. Forth, participants struggle with the process of policy implementation as suggested by Dorey (2005).

Fixsen, Blase, Naoom \& Wallace (2009) propose a model that emphasises the importance of training, coaching, evaluation and administrative support services in the process of policy implementation. As part of that process staff must be trained in elements of the policy and their understanding and quality of work needs to be evaluated. Staff evaluation should be designed to assess the use and outcomes of the skills taught in training, learned on the job, and reinforced and expanded in coaching processes.

Smith \& Shalev Greene (2015) found that police officers were dissatisfied with lack of training about missing persons and while participants recognised the importance of supervision, the demands of the operational role meant that this was not always possible. Thus, their knowledge and understanding of the national or even local policy was limited. It is therefore vital for senior management within the police to prioritise learning opportunities by staff of any new policy or amendments to the existing policy. Participants identified specific concerns about the current definition. The main area for concern was how inclusive the current definition seems to be as it can include almost any person at any given time. In order for the policy to succeed the definition must be clear, coherent and interpreted consistently across police services. It must also be accepted by police officers and civilian staff who are utilising the policy. This is a challenging undertaking, of course. If the definition is too narrow it will lead to the exclusion of relevant cases, if it is too inclusive and it will lose its conceptual meaning and relevance and have profound impact on police workload and budget. 
Interestingly, the same phrase some participants branded as appropriate (e.g. whereabouts cannot be confirmed) was also labelled as confusing. Examining the qualitative material this seems to be because the phrase on its own is open to interpretation and participants identified other components which can be added in order to focus the meaning of the definition. It is important to note that the EC (2013) study found this component to be the most common across EU member states, and the negative sentiment by UK participants may also reflect practitioners' attitudes elsewhere.

Participants identified three components as particularly confusing and requiring clarification. The distinction between absconding and going missing was deemed as ambiguous. It may be partly because people who abscond can also be considered as missing. The difference between the two terms is vital to establish as a high proportion of people reported missing to the police go missing from hospitals or mental health units. Hayden \& Shalev Greene (2018) maintain that a clearer definition will assist in agreeing on duty of care and safeguarding responsibilities of each agency.

The dependency of the police on relationships with other actors (for example, National Health Service, local authority, or social services) leads to communication problems or conflict of interest, which stems from actors seeking to pursue their own particular goal (Dorey, 2005). A clear distinction between 'absconding' and 'missing' can and should impact the wider framework of the policy and clearly determine which agency has a duty of care. This will reduce the number of decision points, where actors need to stop and consider how best to proceed. The clearer the terms and roles each actor has to play, the more effective the policy will be implemented and administered, thus improving national practices, advance safeguarding of vulnerable populations and reduce costs to the police as well as other agencies. 
The component of 'until located' was also found to be confusing to some participants, who raised the question as to what is required of them to officially classify a missing person as 'located'. The method of confirmation was in question, as to whether officers are expected to physically see the person or will a phone call or an email suffice. This seemed to be particularly important in cases where the missing person was living abroad or where they expressed free will as adults to cut contact with their relatives. Thus, the framework within the policy should set clear guidelines as to what the term 'locating' the missing person means and what actions are expected from officers to determine that.

The determination of 'well-being or otherwise' is often intertwined with locating a missing person but was also deemed as confusing in the definition. While it recognised the vulnerability of people who go missing, a few participants suggested that the term should explicitly acknowledge well-being to mean physical as well as mental and emotional wellbeing. The difficulty is that police are usually not trained to determine the actual physical and mental or emotional well-being of a person as many health factors can be hidden. More importantly, as part of the policy framework there should be guidelines on determining the well-being and identify the elements that term includes.

Participants identified two components they wanted to see added to the definition. Most importantly was the element of risk to and vulnerability of the missing person. This was the other most common component in the EC (2013) study. This component was judged to be a fundamental part of the process of uncovering the context as to why the person disappeared and what should be the police response to it. This is because the risk assessment process determine the resources invested in locating the missing person.

Participants also referred to time as being a component they wanted added. Reference to time has been rejected by EC (2013) study as well as senior level officials in law enforcement 
agencies in the UK and the charity Missing People. This is due to concerns that an unnecessary delay in reporting a person missing to the police puts people at a great risk of harm, and makes it a more difficult task for search and rescue operations to find them quickly.

Rather than relating to a set of hours before reporting a person missing, this point seems to concern participants' wish that the persons making a report will only be able to do so after conducting an initial search and exhausted reasonable efforts to locate the missing person. This stems from previous discussions about duty of care by various agencies that look after the person who went missing, such as children who go missing from care homes (Hayden \& Shalev Greene, 2018). One can also mitigate this by focusing on a public campaign to educate the public on what information the police is seeking when a report is made to make sure certain steps have already been taken to find the person prior to the report. This could be included in an updated policy framework.

All the components mentioned above should also be considered in the context of the content of a missing person definition. Yet, it should also be part of a broader debate as to the role and responsibilities of the police in protecting the public and enhancing community safety. First, this study supports the work of Vitale (2017). Instead of treating social problems as policing problems, what is required are more mental health specialists, more social workers and youth workers, and more community-based programmes. In short, what is needed are more state welfare interventions and less regressive state control in the lives of the marginalised and the vulnerable. Much like Pratt (2007) Pratt et al. (2013) and Wacquant (2010) before him, Vitale (2017, p.27) recognises that "political leaders have embraced a neoconservative politics that sees all social problems as police problems". The state has abdicated from the social sphere (Garland, 2012; Simon, 2007; Wacquant, 2010), but seeks to govern through the punitive turn in criminal justice policy. 
Second, one of the core issues with lack of standardised definition is it impact on recording of incidents. This is because the data is a snapshot in time which misses the complexities of social interaction, social activity, and social meaning. As Hope (2007, p.62) notes "there are considerable difficulties of interpretation and inference, including problems of partiality, bias and distortion, raised by the essential selectivity of the available data". Data on recorded missing person incidents drawn from police databases such as the COMPACT or NICHE are no different to the recording of crime. Beyond that, Hope (2014) also notes the influence of third-party pressures beyond the complainant and the police on recording practice. The pressures come from prevailing senses of morality, actuaries, police performance targets, and recording standards.

Third, responding to reports of missing persons represents one of the biggest demands on the resources of law enforcement agencies (Fyfe, Stevenson \& Woolnough., 2015). It is vital to remember that the absence, even partial, of resources will inevitably have a detrimental impact on the successful implementation of the policy (Dorey, 2005).

Finally, the demand on police resources is not only financial (Shalev Greene \& Pakes, 2013) but also qualitative as missing person investigations pose particular challenges to investigating officers. Police face a range of dilemmas with each report as they must quickly establish whether the person is in fact 'missing' and determine which agency is best suited to respond. For example, a teenager living in a care setting who informs their carer they are going out to see their friends and is half an hour late. Thus, the policy must identify relative success or police officers and staff will have to prioritisetheir decisions and actions based on what they consider urgent or feasible given the unavoidable resource constraints in which they operate (Dorey, 2005). 
This study has important implications for policy process and implementation not only in the UK but in other countries as well. For instance, this study contributes to the body of evidence indicating that police officers and civilian staff are not content with the missing person policy (Smith \& Shalev Greene, 2015). This study indicates that police officers and civilian staff vary in their interpretation of the term missing person and the type of cases this term should include, thus explaining the variety of practices across the UK in utilising the national policy. These finding support the EC (2013) recommendation that all sectors should hold a common currency and terminology as this will improve standards of response to missing person incidents. Finally, the results highlight the need for policy level intervention by possibly changing the current definition to a definition which considers the real world experience of police officers and civilian staff as well as actors from other agencies.

\section{Limitations and Directions for Future Research}

Implications of our findings should be considered within the context of limitation to the study design. Responses may have been affected by the phrasing of the survey questions. Had participants been given an opportunity to 'vote' on the suitability of each component within the current definition, this may have led to different responses. Furthermore, the sample was not representative of the proportionate number of police officers working in these regions, and responses from Wales were low. Future research may want to break down the definition into each component and ask participants to respond in more precise terms as to whether they approve of it or not. It may also be useful to ask participants from various organisations to choose from a variety of missing person definitions from the UK and other countries, and explain their choice. This was already done by Shalev Greene (2019) in Northern Ireland and can be replicated across the UK and internationally.

\section{Conclusion and Recommendations}


This study examined police officers and civilian staff's perceptions of the missing person definition, published by the College of Policing (2016). It is the first study to empirically examine the viewpoint of missing person policy implementers.

Overall, this study found that most police officers and civilian staff have negative perceptions of the current missing person definition, which inhibits successful implementation of the policy. The definition is deemed too inclusive and there are three components participants find particularly confusing and two components they wish to add or change. However, many of the components raised could be jointly addressed with reviewing the current definition as well as the policy framework and making sure the framework is known and used on a consistent basis throughout different police forces.

Our findings support six key recommendations to policy makers. First, an explicit distinction needs to be made between a missing person and a person who absconds. The construction and deployment of two separate definitions of missing persons should be considered. Second, the existing definition should include two new components, e.g., acknowledging the risk and vulnerability of the missing person, and that initial efforts were made by the person reporting someone missing to locate them. Third, the term 'locating' should be made clearer, as this will shape the actions which are expected from police officers. Fourth, the phrase 'well-being or otherwise' should be discussed explicitly in relation to the physical and mental well-being of the missing person, and how officers are expected to determine these. Fifth, policy makers should consider clarifying the role of the police in response to missing person reports within the broader context of police roles and responsibilities. Sixth, the policy makers should also consider clarifying the duty of care of each agency when a person goes missing and was in the care or guardianship of other agencies or the state. These recommendations should be considered within a revised definition of missing persons as well as offering additional guidance within a national policy framework. 


\section{References}

All-Party Parliamentary Group on Runaway and Missing Children and Adults (2017).Briefing report on the roundtable on children who go missing and are criminally exploited by gangs. Retrieved from: https://www.childrenssociety.org.uk/what-we-do/policyand-lobbying/appg-on-runaway-and-missing-children-and-adults

Association of Chief Police Officers (ACPO) (2005) Guidance of management and recording of investigation of missing persons.

Association of Chief Police Officers (ACPO) (2013) Interim Guidance on the management, recording and investigation of missing Persons 2013. Retrieved from: http://www.nationalcrimeagency.gov.uk/about-us/what-we-do/specialist-capabilities/missingpersons-bureau/information-for-police

Barton, A., \& Johns, N. (2012). The policy making process in the criminal justice system. New York: Routledge.

Bovens, M., Hart, P., \& Kuipers, S. (2006). The politics of policy evaluation. In M. Moran, M. Rein \& R. R. Goodin (eds). The Oxford handbook of public policy. Oxford: Oxford University Press, 319-335.

Braun, V., \& Clarke, V. (2006). Using thematic analysis in psychology. Qualitative Research in Psychology, 3(2), 77-101.DOI: 10.1191/1478088706qp063oa 
Butler, R., \& Parr, H. (Eds.). (2005). Mind and body spaces: Geographies of illness, impairment and disability. London: Routledge.

Cohen, R. (2017). The Force and the Resistance: Why Changing the Police Force Is Neither Inevitable, Nor Impossible. University of PennsylvaniaJournal of Law and Social Change, 20(2), 105-123.

College of Policing (2015). College of Policing analysis: Estimating demand on the police service. Retrieved from: https://www.opendemocracy.net/en/openjustice/we-dont-need-morepolice-we-need-shift-of-responsibilities/

College of Policing (2016). Major investigations and public protection: Missing persons. Retrieved from: https://www.app.college.police.uk/app-content/major-investigation-andpublic-protection/missing-persons/

College of Policing (2017). POLKA. Retrieved from: http://www.college.police.uk/What-wedo/Research/polka/Pages/POLKA.aspx

Dorey, P. (2005). Policy making in Britain: An introduction. Sage.

Dunn, W. N. (2015). Public policy analysis. Routledge.

Edkins, J. (2011). Missing: Persons and politics. Cornell University Press. 
European Commission (2013). Missing children in the European Union. Mapping, data collection and statistics. European Union. Retrieved from: http://missingchildreneurope.eu/catalog/documentid/158

Fixsen, D. L., Blase, K. A., Naoom, S. F., \& Wallace, F. (2009). Core implementation components. Research on social work practice, 19(5), 531-540. https://doi.org/10.1177/1049731509335549

Freeman, R. (2006). Learning in public policy. In M. Moran, M. Rein \& R. R. Goodin (eds). The Oxford handbook of public policy. Oxford: Oxford University Press, pp. 367-388.

Fyfe, N. R., Stevenson, O., \& Woolnough, P. (2015). Missing persons: The processes and challenges of police investigation. Policing and Society, 25(4), 409-425. https://doi.org/10.1080/10439463.2014.881812

Garland, D. (2012). The culture of control: Crime and social order in contemporary society. University of Chicago Press.

Harvey, T. R., \& Broyles, E. A. (2010). Resistance to change: A guide to harnessing its positive power. R\&L Education.

Hayden, C., \& Shalev-Greene, K. (2018). The blue light social services? Responding to repeat reports to the police of people missing from institutional locations. Policing and Society, 28(1), 45-61. https://doi.org/10.1080/10439463.2016.1138475 
Her Majesty's Inspector of Constabulary and Fire \& Rescue Service (HMICFRS)(2016). Missing children: Who cares? The police response to missing and absent children. Retrieved from: http://www.justiceinspectorates.gov.uk/hmicfrs/wp-content/uploads/missing-childrenwho-cares.pdf

Hill, M., \& Varone, F. (2014).The public policy process. Routledge.

Hobbs, S., \&Hamerton, C. (2014). The making of criminal justice policy. London: Roubledge.

Holmes, L., Woolnough, P., Gibb, G. J., Lee, R. M., Crawford, M. (2014). Missing persons and mental Health. Missing People. Retrieved from: https://www.missingpeople.org.uk/downloads/missing-persons-and-mental-health

Home Office (2011).Guidance Missing Children and Adults Strategy.

https://www.gov.uk/government/publications/missing-children-and-adults-strategy

Hope, T. J. (2007). Theory and method: the social epidemiology of crime victims. In Handbook of Victims and Victimology (pp.62-90). Willan.

Hope, T. J. (2014). The effect of 'third party'pressure on police crime recording practice. Enquiry into Crime Statistics Public Administration Select Committee. House of Commons. Retrieved from:

https://www.researchgate.net/publication/330093698 THE EFFECT OF \%27THIRD PAR TY\%27 PRESSURE ON POLICE CRIME RECORDING PRACTICE Evidence to the 
_House_of_Commons_Public_Administration_Select_Committee_PASC_Inquiry_into_Crim

e Statistics

Howlett, M., Ramesh, M., \& Perl, A. (2009). Studying public policy: Policy cycles and policy subsystems (Vol. 3). Oxford: Oxford University Press.

International Centre for Missing \& Exploited Children (ICMEC) \& United Nations Children's Fund (UNICEF)(2011). Missing children in Central America: Research of practices and legislation on prevention and recovery. Retrieved from: https://www.icmec.org/about-the-research-initiative/

International Centre for Missing \& Exploited Children (ICMEC)(2015). Model missing child framework. Retrieved from: https://www.icmec.org/wp-content/uploads/2016/07/ModelMissing-Children-Framework-FINAL_EN.pdf

International Centre for Missing \& Exploited Children (ICMEC)(2016a). Missing children in Southeast Asia: Model framework \& regional review. Retrieved from: https://www.icmec.org/about-the-research-initiative/

International Centre for Missing \& Exploited Children (ICMEC)(2016b). Missing Children Assessment and Recommendations Best Practices Guide. Belarus, Canada, Finland, Kazakhstan, Russia, and the United States.Retrieved from: https://www.icmec.org/about-theresearch-initiative/

Lipsky, M. (1980). Street-level bureaucracy: Dilemmas of the individual in public service. Russell New York: Sage Foundation. $1^{\text {st }}$ edition. 
Lipsky, M. (2010).Street-level bureaucracy, 30th Annual expanded edition: Dilemmas of the individual in public service. New York: Russell Sage Foundation. $2^{\text {nd }}$ Edition.

Missing People (n.d) What is missing? Retrieved from: https://www.missingpeople.org.uk/about-us/about-the-issue/research/76-

keyinformation $2 . h t m l$

Morewitz, S. J. \& Sturdy Colls, C. (Eds.)(2016) Handbook of missing persons. Springer International Publishing.

Moscovici, S., \& Halls, W. D. (1993). The invention of society: Psychological explanations for social phenomena. Policy Press.

Moyson, S., Scholten, P., \&Weible, C. M. (2017). Policy learning and policy change: Theorizing their relations from different perspectives. Policy and Society, 36(2), 161177.https://doi.org/10.1080/14494035.2017.1331879

National Crime Agency (2016). Missing Persons Data Report 2014/2015. UK Missing Persons Bureau. Retrieved from: www.nationalcrimeagency.gov.uk/.../696-missing-personsdata-report-2014-2015/file

National Crime Agency (2017). Missing Persons Data Report 2015/2016. UK Missing Persons Bureau. Retrieved from: http://missingpersons.police.uk/engb/resources/downloads/missing-persons-statistical-bulletins 
Newman, J., \& Yeates, N. (2008). Social justice: Welfare, crime and society. Open University Press.

O'Hara, M. (2015).Austerity bites: A journey to the sharp end of cuts in the UK. Policy Press.

Pratt, J. (2007). Penal populism. Routledge.

Pratt, J., Brown, D., Brown, M., Hallsworth, S., \& Morrison, W. (Eds.). (2013). The new punitiveness. Routledge.

Shalev Greene, K. (2019). A multi-agency evaluation of the definition of a missing person in Northern Ireland. Internal report submitted to Northern Ireland Joint Working Group.

Shalev Greene, K., \& Alys, L. (2016)(Eds). Missing persons: A handbook of research. London: Routledge.

Shalev Greene, K., \& Pakes, F. (2013). The cost of missing person investigations: Implications for current debates. Policing: A Journal of Policy and Practice, 8(1), 27-34. https://doi.org/10.1093/police/pat036

Simon, J. (2007). Governing through crime: How the war on crime transformed American democracy and created a culture of fear. Oxford University Press. 
Smith, R. \& Shalev Greene, K. (2015). 'Recognizing risk: the attitudes of police supervisors to the risk assessment process in missing person investigations'. Policing: A Journal of Policy and Practice, 9, 4(1), 352-361, DOI: https://doi.org/10.1093/police/pav016

Stevenson, O., Parr, H., Woolnough, P., and Fyfe, N. (2013). Geographies of Missing People: Processes, Experiences, Responses [Online]. Project Report.University of Glasgow, Glasgow, UK.

United Nationas Office on Drugs and Crime (2015). International Classification of Crime for Statistical Purposes (ICCS). Retrieved from: https://www.unodc.org/unodc/en/data-andanalysis/statistics/iccs.html

Vitale, A. S. (2017). The end of policing. Verso Books.

Wacquant, L. (2010, June). Crafting the neoliberal state: workfare, prisonfare, and social insecurity 1. In Sociological Forum (Vol. 25, No. 2, pp. 197-220). Oxford, UK: Blackwell Publishing Ltd. 